\title{
Prevalence and Prognostic Impact of Hypernatremia in Sepsis and Septic Shock Patients in The Intensive Care Unit: A Single Centre Experience
}

\author{
Mohamed Shirazy 1,2*, Islam Omar ${ }^{3,4}$, Duaa Abduljabbar ${ }^{5}$, Kamel Bousselmi², Maryam \\ Alkhaja5$^{5}$, Anis Chaari², Vipin Kauts², Karim Hakim² \\ ${ }^{1}$ Emergency Department, University Hospitals of Morecambe Bay NHS Foundation Trust, United Kingdom \\ 2 Critical Care Department, King Hamad University Hospital, Kingdom of Bahrain \\ 3 Surgical Department, University Hospitals of Morecambe Bay NHS Foundation Trust, United Kingdom \\ 4 Surgical Department, King Hamad University Hospital, Kingdom of Bahrain \\ 5 Internal Medicine department, King Hamad University Hospital, Kingdom of Bahrain
}

\begin{abstract}
Introduction: Hypernatremia is a commonly associated electrolyte disturbance in sepsis and septic shock patients in the ICU. The objective of this study was to identify the prognostic value of hypernatremia in sepsis and septic shock

Material and Methods: A prospective study conducted on sepsis and septic shock patients diagnosed prior to admission in the ICU in King Hamad University Hospital, Bahrain from January 1st 2017 to February 28th 2019. Data including age, sex, comorbidities, source of sepsis, sodium levels on days one, three, and seven. Data was correlated with the outcome (survival/death and the length of ICU stay). Results: Patients included were 168, 110 survived, and 58 died. Hypernatraemia at day seven was associated with significantly higher mortality $(P=0.03)$. Hypernatraemia at Day1was associated with a significantly prolonged stay in the ICU $(p=0.039)$. Multivariate analysis to identify the independent predictors of mortality revealed that immunosuppression and hypernatraemia at Day7 proved to be independent predictors of mortality ( $P=0.026$ and 0.039 respectively). Conclusion: Hypernatremia can be an independent predictor of poor outcome in septic and septic shock patients in the ICU.
\end{abstract}

Keywords: sepsis , hypernatremia, biomarkers

Received: 19 October 2019 / Accepted: 12 January 2020

\section{INTRODUCTION}

Sepsis and septic shock are among the most prevalent causes of intensive care unit (ICU) admissions. They account for around $10-50 \%$ of the mortality rate, which remains high despite extensive research, the Surviving Sepsis Campaign, and national core measures [1-5].

Sepsis is defined as "Organ dysfunction that threatens the patient's life caused by the impaired host response to infection" [6]. However, septic shock is defined as hypotension and serum lactate level greater than two $\mathrm{mmol} / \mathrm{L}$, as well as not responding to adequate fluid resuscitation requiring the use of vasopressors to maintain the mean blood pressure of $65 \mathrm{~mm} \mathrm{Hg}$ or higher [7]. Sepsis and septic shock are considered medical emergencies that require early identification and immediate management [8-16].

Acute hypernatremia is considered one of the features of homeostasis disturbances, which is common in septic patients with an incidence reaching up to $47 \%$ [17]

Finding biomarkers which predict the outcome of sepsis is challenging $[18,19]$. Since electrolyte imbalance, specifically hypernatremia, is one of the commonest problems associated with sepsis and septic shock patients [20, 21]. It is, therefore, of current interest to study the evolution of sepsis in patients who have been shown to have hypernatremia. 
The aim of the present study is to identify the prevalence and prognostic impact of hypernatremia on sepsis and septic shock patients

\section{a MATERIALS AND METHODS}

A prospective observational study, conducted on sepsis and septic shock patients that were admitted in the Intensive Care Unit (ICU) of King Hamad University Hospital, Kingdom of Bahrain over 25 months, starting from January 1st, 2017 till February 28th, 2019.

The diagnosis of sepsis and septic shock was made prior to the ICU admission.

Sepsis and septic shock were defined according to the Sepsis 3 definition using the Quick Sofa score of 2 or more $[6,7]$, and hypernatremia was defined as $[\mathrm{Na}+]>145 \mathrm{mmol} / \mathrm{L}$.

The excluded patients were those aged $<18$ years, those planned for "end of life care", and patients with a previous diagnosis of hyperaldosteronism, Cushing syndrome, or diabetes insipidus.

\section{Data collection methods, instruments used, and measurements}

Data collected included demographic data (age, sex), comorbidities, source of sepsis, sodium levels on days one, three, and seven.

The source of sepsis was confirmed via a routine sepsis workup that included radiological evidence, culture and sensitivity of blood, sputum, and urine, abdominal fluid drain culture, tissue culture, and cerebrospinal fluid (CSF) analysis and cultures for suspected cases.

Various variables including demographic data, comorbidities, source of sepsis, and sodium levels on days 1,3 , and 7 were assessed against the outcome parameters, that were the length of ICU stay and mortality.

To test the predictability of sodium levels, patients were divided into patients with hypernatraemia $(\mathrm{Na}$ level $>145 \mathrm{mmol} / \mathrm{l})$, eunatraemia (Na level $=135-145$ $\mathrm{mmol} / \mathrm{l})$ or hyponatraemia $(\mathrm{Na}$ level $<135 \mathrm{mmol} / \mathrm{l})$ on days 1,3 , and 7 post-admission to the ICU

\section{Data management and analysis plan}

The data was analyzed using SPSS version 22 and Microsoft Excel 2016.

The level of significance was set at 0.05

\section{RESULTS}

Of 224 patients admitted to the ICU with sepsis and septic shock, 168 patients fulfilled the inclusion criteria. Demographic data, comorbidities, and sources of sepsis were analysed (Table 1).

One hundred and ten patients survived, and fiftyeight died. Regarding comorbidities, chronic kidney disease (CKD), ischemic heart disease (IHD), and immunosuppressed patients had significantly higher mortality. ( $\mathrm{P}=0.046,0.046$, and 0.002$)$ respectively. (Table 1 )

$\mathrm{CKD}$ and diabetes mellitus (DM) were associated with a significantly longer length of stay. $(\mathrm{P}=0.003$, 0.011 ) respectively (Table 2 ).

Sodium levels were recorded and assessed against the outcome parameters. Hypernatremia at Day1 and Day3 did not show any positive correlation with outcome. However, hypernatraemia at day seven was associated with significantly higher mortality $(\mathrm{P}=0.388$, 0.709 , and 0.030 , respectively). (Table 3) However, hypernatraemia at Day1 was associated with a significantly prolonged stay in the ICU $(\mathrm{p}=0.039)$. (Table 4$)$

Multivariate analysis to identify the independent predictors of mortality (Table 2 ) revealed that immunosuppression and hypernatraemia at Day7 proved to be independent predictors of mortality $(\mathrm{P}=0.026$ and 0.039 respectively) (Table 5 ).

\section{Discussion}

The results of the study showed that hypernatremia on the Day7 was associated with high mortality in septic patients. Moreover, hypernatremia on the Dayl was associated with prolonged length of ICU stay of septic patients.

The definition of hypernatremia used in this study was a serum sodium concentration $>145 \mathrm{mmol} / \mathrm{L}$ $[22,23]$. This serum sodium level was considered as the upper limit of normal and was used to test the correlation between even the mildest degrees of hypernatremia in septic patients and the outcome represented by both ICU mortality and length of stay in the ICU.

Previous studies have reported higher morbidity and mortality in the general ICU population with hypernatremia. They defined hypernatremia as serum sodium $>149 \mathrm{mmol} / \mathrm{l}$ [23-30].

In the current study, the decision was taken to test the effect of both initial and developed hypernatremia 
Table 1. Relationships between Outcome and Demographic data, Comorbidities, and Sources of Sepsis ( $n=168)$

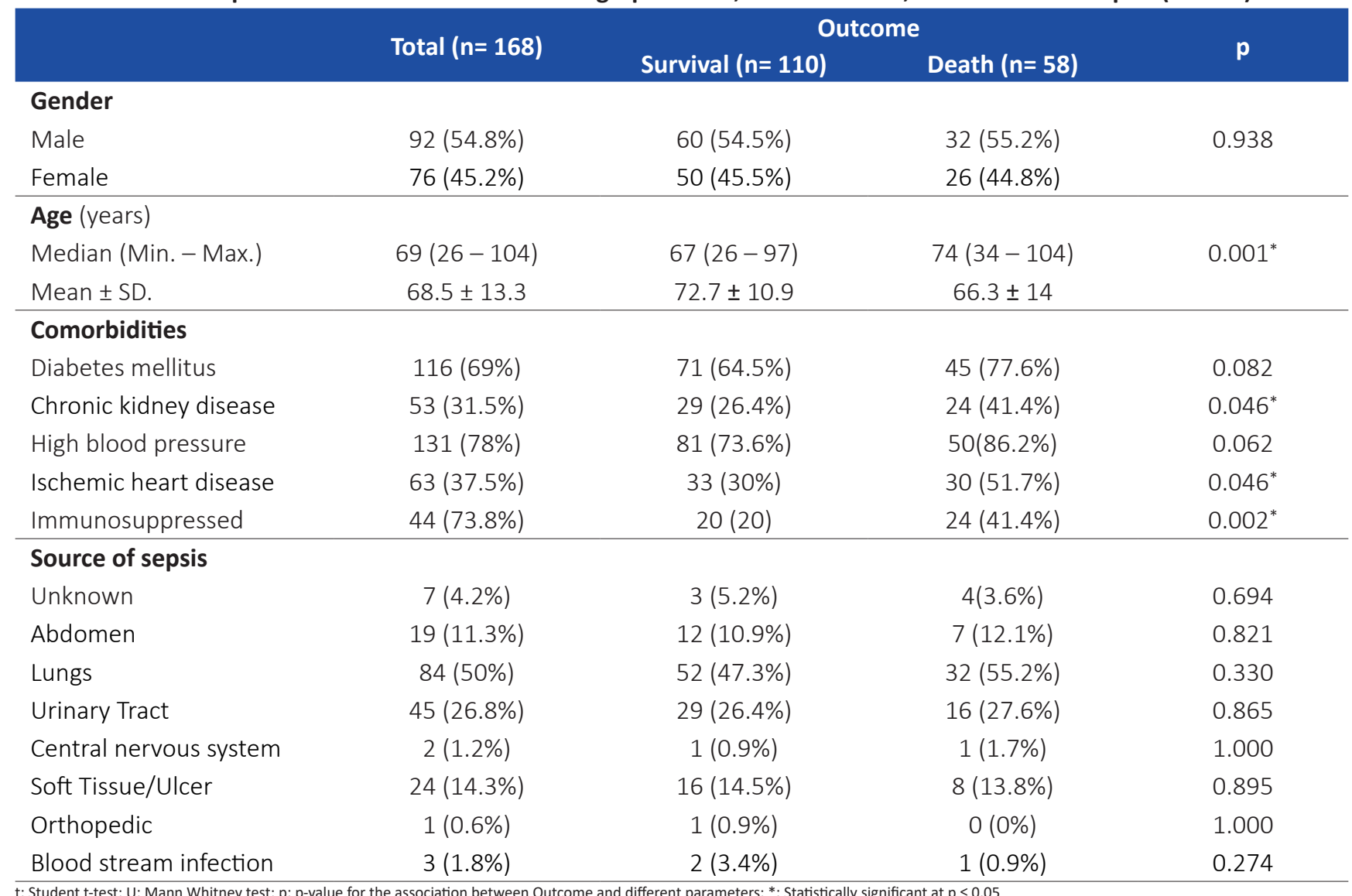

Table 2. Relationships between the length of ICU stay and Demographic data, Comorbidities, and Source of Sepsis ( $n=168)$

\begin{tabular}{|c|c|c|c|}
\hline \multirow{3}{*}{ Gender } & \multicolumn{2}{|c|}{ length of ICU stays } & \multirow{2}{*}{$\mathbf{p}$} \\
\hline & \multirow[t]{2}{*}{ Median (Min. - Max.) } & \multirow[t]{2}{*}{ Mean \pm SD. } & \\
\hline & & & \multirow{3}{*}{0.892} \\
\hline Male & $10(1-120)$ & $17 \pm 20.5$ & \\
\hline Female & $9.5(1-210)$ & $21.8 \pm 32.3$ & \\
\hline \multicolumn{4}{|l|}{ Comorbidities } \\
\hline Diabetes mellitus & $12(1-210)$ & $21.8 \pm 29.5$ & $0.011^{*}$ \\
\hline Chronic kidney disease & $14(1-124)$ & $25.2 \pm 26.1$ & $0.003^{*}$ \\
\hline High blood pressure & $10(1-210)$ & $20.8 \pm 28.9$ & 0.229 \\
\hline Ischemic heart disease & $10(1-210)$ & $20.1 \pm 30.5$ & 0.999 \\
\hline Immunosuppressed & $10.5(2-120)$ & $21.5 \pm 25.7$ & 0.406 \\
\hline \multicolumn{4}{|l|}{ Source of sepsis } \\
\hline Unknown & $21(5-120)$ & $42.7 \pm 44.2$ & $0.04^{6 *}$ \\
\hline Abdomen & $19(3-57)$ & $22.9 \pm 19.3$ & 0.101 \\
\hline Lungs & $11.5(1-210)$ & $24 \pm 34.1$ & 0.292 \\
\hline Urinary Tract & $9(1-120)$ & $16 \pm 22.5$ & 0.277 \\
\hline Central nervous system & $20(15-25)$ & $20 \pm 7.1$ & 0.371 \\
\hline Soft Tissue/Ulcer & $12.5(2-68)$ & $16.6 \pm 15.8$ & 0.652 \\
\hline Orthopedic & \multicolumn{2}{|c|}{$5^{\#}$} & - \\
\hline Bloodstream infection & $8(2-21)$ & $10.3 \pm 9.7$ & 0.606 \\
\hline
\end{tabular}


Table 3. Relation between Outcome and Sodium levels on Days 1, Days 3, and Days $7(n=168)$

\begin{tabular}{|c|c|c|c|c|}
\hline & \multicolumn{4}{|c|}{ Outcome } \\
\hline & $10 t a l \mid(1)=100)$ & Survival $(n=110)$ & Death $(n=58)$ & $\mathbf{p}$ \\
\hline \multicolumn{5}{|l|}{ Serum Na (day1) } \\
\hline Low $(<135)$ & 67 (39.9\%) & $42(38.2 \%)$ & $25(43.1 \%)$ & \\
\hline Normal (135 - 145) & $91(54.2 \%)$ & $64(58.2 \%)$ & 27 (46.6\%) & \\
\hline High (>145) & $10(6 \%)$ & $4(3.6 \%)$ & $6(10.3 \%)$ & \\
\hline Median (Min. - Max.) & 136 (109-152) & 136 (114-151) & 135 (109-152) & \multirow{2}{*}{0.388} \\
\hline Mean \pm SD & $135.6 \pm 6.6$ & $135.6 \pm 5.9$ & $134.8 \pm 7.9$ & \\
\hline \multicolumn{5}{|l|}{ Serum Na (day3) } \\
\hline Low $(<135)$ & $39(26.4 \%)$ & $25(25 \%)$ & $14(29.2 \%)$ & \multirow{5}{*}{0.709} \\
\hline Normal (135 - 145) & $95(64.2 \%)$ & 69 (69\%) & $26(54.2 \%)$ & \\
\hline High (>145) & $14(9.5 \%)$ & $6(6 \%)$ & $8(16.7 \%)$ & \\
\hline Median (Min. - Max.) & 138 (113-155) & 138 (118-155) & 137 (113-152) & \\
\hline Mean \pm SD. & $137.9 \pm 5.8$ & $137.8 \pm 5$ & $137.8 \pm 7.3$ & \\
\hline \multicolumn{5}{|l|}{ Serum Na (day7) } \\
\hline Low $(<135)$ & $22(19.5 \%)$ & $16(22.2 \%)$ & $6(14.6 \%)$ & \\
\hline Normal (135 - 145) & $70(61.9 \%)$ & $47(65.3 \%)$ & $23(56.1 \%)$ & \\
\hline High (>145) & $21(18.6 \%)$ & $9(12.5 \%)$ & $12(29.3 \%)$ & \\
\hline Median (Min. - Max.) & 139 (120-154) & $138(120-154)$ & 141 (130-152) & \multirow{2}{*}{$0.030^{*}$} \\
\hline Mean \pm SD. & $139.3 \pm 6.2$ & $138.3 \pm 6$ & $141.2 \pm 6.3$ & \\
\hline
\end{tabular}

Table (4): Relation between the Length of ICU stay and Sodium levels on Days 1, Days 3, and

Days 7 ( $n=168)$

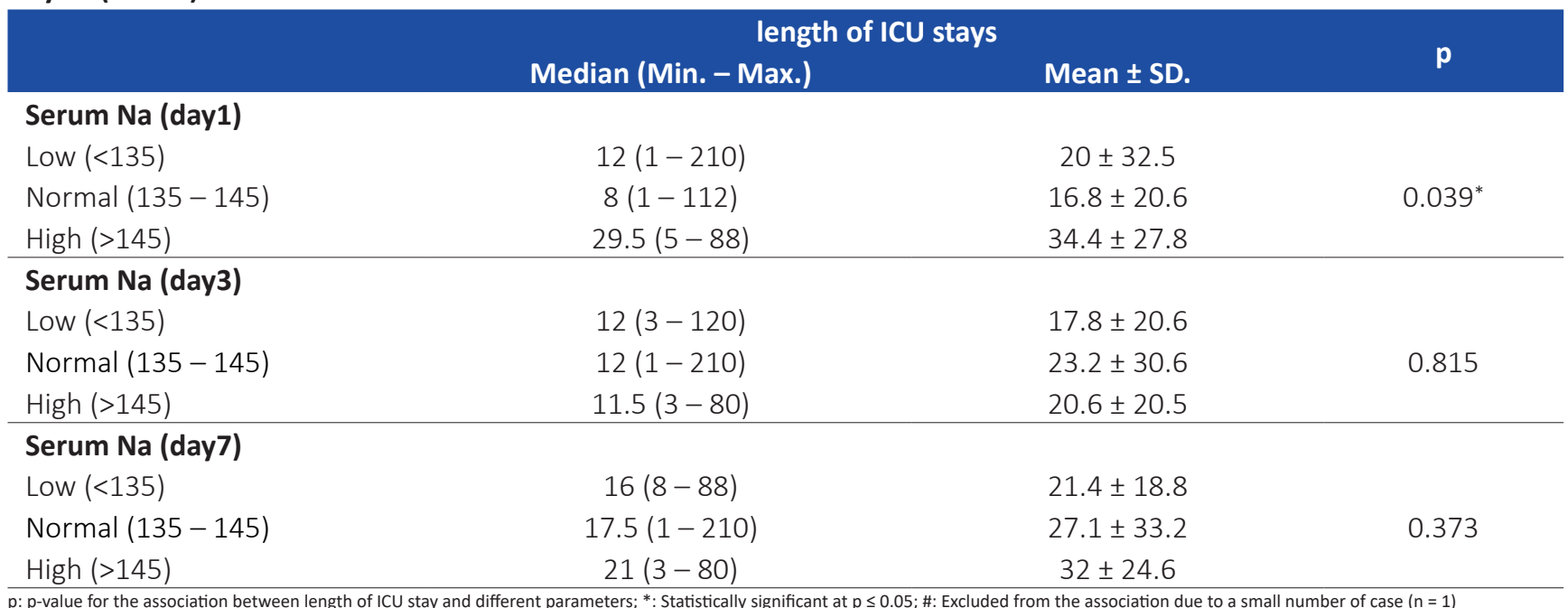

in ICU septic patients. To do this, sodium levels on the Day1, Day3, and Day7 were collected and examined. The correlation between the duration of hypernatremia in septic ICU patients and the outcome was not calculated. Both O'Donoghue et al. (2009) and Michael D. Waite et al. (2013) failed to find an association between the duration of hypernatremia and mortality $[24,31]$.
A study by Van De Louw et al. (2014) showed that $31 \%$ of them developed hypernatremia by the fifthday post-ICU admission [37]. However, another study showed that $47.1 \%$ of the patients developed hypernatremia during their stay in an ICU [38] compared to $18.7 \%$ by the Day 7 in the present study. The mechanism of the development of hypernatremia can be due 
Table 5. Univariate and multivariate analysis for independent predictors of mortality

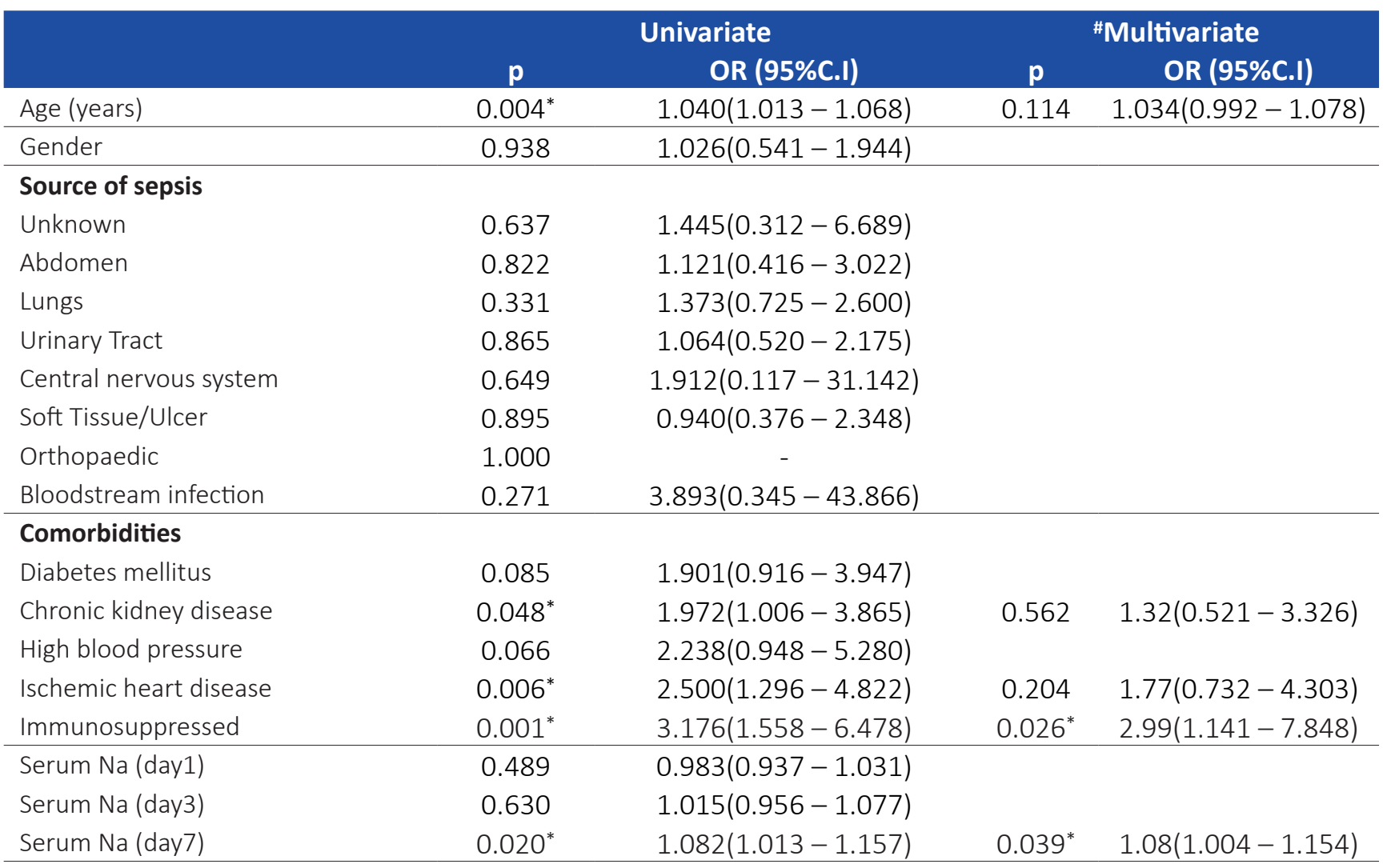

to dehydration associated with fever, hyperglycaemia, diarrhoea, nasogastric drainage, in addition to the loss of the patients' ability to maintain their water intake while being sedated and mechanically ventilated [31].

Besides, other mechanisms of hypernatremia can be the volume of $0.9 \%$ saline infused during the first 48 hours of admission [31], renal impairment together with renal water loss $[17,32]$, and the administration of loop diuretics $[34,35]$.

In our studied group, none of the patients received any diuretics. However, $31.5 \%$ were known to have chronic kidney disease (CKD). Additionally, all patients received the same initial resuscitation as recommended by the surviving sepsis campaign guidelines using crystalloids, $0.9 \%$ saline or lactated Ringer's solution [4]. The volume of any further fluid was directed by various techniques, which included the passive leg raising test, pulse contour cardiac output (PiCCO), and echocardiography. Moreover, continuous renal replacement therapy (CRRT) was commenced early in all patients who had or developed acute kidney injury (AKI) in the ICU. Previous studies have shown that the use of renal replacement therapy, either continuous or intermittent, will reduce the incidence of hypernatremia $[43,44]$.
Accordingly, the previously mentioned management strategies adopted in our study group may explain the lower incidence of hypernatremia (18.7\%).

In accord with previous observational studies on hypernatremia and sepsis, this prospective study shows significantly higher mortality rates and prolonged ICU stay in patients with hypernatremia $[37,38]$.

Although our study was conducted prospectively on a large number of patients, there were several limitations. Firstly, the correlation between the degree and duration of hypernatremia with the outcome was not tested. Secondly, only the effect of hypernatremia on Day 1, Day 3 and Day 7, was studied. The correlation of hypernatremia with sodium levels measured daily for at least the first ten days of admission may have given more precise results.

\section{CONCLUSION}

Hypernatremia can be an independent predictor of poor outcome in septic and septic shock patients in the ICU.

\section{CONFLICT OF INTEREST}

None to declare. 
Available online at: www.jccm.ro

\section{ACKNOWLEDGEMENTS}

No grants, contracts, or any other form of financial support were received for this study.

\section{REFERENCES}

1. Mohan A, Shrestha P, Guleria R, et al. Development of a mortality prediction formula due to sepsis/ severe sepsis in a medical intensive care unit. Lung India; 2015; 2015 JulAug;32(4):313-9

2. Andre S.F, Susana M.V, Uzay K, et al. Mortality prediction of septic shock patients using probabilistic fuzzy systems. Applied Soft Computing. 2016 May (42); 194-203.

3. Rhee C, Dantes R, Epstein L, et al. Incidence and trends of sepsis in US hospitals using clinical vs claims data, 2009-2014. JAMA 2017 Oct 3;318(13):1241-1249.

4. Coopersmith CM, De Backer D, Deutschman CS, et al. Surviving sepsis campaign: research priorities for sepsis and septic shock. Crit Care Med. 2018 Aug;46(8):1334-1356.

5. Micek ST, Roubinian N, Heuring T, et al. Before-after study of a standardized hospital order set for the management of septic shock. Crit Care Med. 2006 Nov;34(11):2707-13.

6. Singer M, Deutschman CS, Seymour CW, et al. The third international consensus definitions for sepsis and septic shock (sepsis-3). 2016 Feb 23;315(8):801-10.

7. Shankar-Hari M, Phillips GS, Levy ML, et al. Developing a New Definition and Assessing New Clinical Criteria for Septic Shock: For the Third International Consensus Definitions for Sepsis and Septic Shock (Sepsis-3). JAMA. 2016 Feb 23;315(8):77587

8. Levy MM, Rhodes A, Phillips GS, et al. Surviving Sepsis Campaign: Association between performance metrics and outcomes in a 7.5-year study. Crit Care Med. 2015 Jan;43(1):312

9. Damiani E, Donati A, Serafini G, et al. Effect of performance improvement programs on compliance with sepsis bundles and mortality: A systematic review and meta-analysis of observational studies. PLoS One. 2015 May 6;10(5):e0125827

10. Rhodes A, Phillips G, Beale R, et al. The Surviving Sepsis Campaign bundles and outcome: Results from the International Multicentre Prevalence Study on Sepsis (the IMPreSS study). Intensive Care Med. 2015 Sep;41(9):1620-8

11. Seymour CW, Gesten F, Prescott $\mathrm{H}$, et al. Time to treatment and mortality during mandated emergency care for sepsis. $\mathrm{N}$ Engl J Med. 2017 Jun 8;376(23):2235-2244

12. Liu VX, Morehouse JW, Marelich GP, et al. Multicenter implementation of a treatment bundle for patients with sepsis and intermediate lactate values. Am J Respir Crit Care Med. 2016 Jun 1;193(11):1264-70.

13. Leisman DE, Doerfler ME, Ward MF, et al.: Survival benefit and cost savings from compliance with a simplified 3-hour sepsis bundle in a series of prospective, multisite, observational
The Journal of Critical Care Medicine 2020;6(1) • 57

cohorts. Crit Care Med. 2017 Mar;45(3):395-406

14. Ferrer R, Martin-Loeches I, Phillips G, et al.: Empiric antibiotic treatment reduces mortality in severe sepsis and septic shock from the first hour: Results from a guideline-based performance improvement program. Crit Care Med. 2014 Aug;42(8):1749-55

15. Kumar A. Systematic bias in meta-analyses of time to antimicrobial in sepsis studies. Crit Care Med. 2016 Apr;44(4):e234-5.

16. Rhodes A, Evans LE, Alhazzani W, et al. Surviving Sepsis Campaign: International guidelines for management of sepsis and septic shock: 2016. Crit Care Med. 2017 Mar;45(3):486552.

17. Ni-HB, Hu XX, Huang XF et al. Risk Factors and Outcomes in Patients with Hypernatremia and Sepsis. Am J Med Sci. 2016 Jun;351(6):601-5.

18. Charles PE, Gibot S. Predicting outcome in patients with sepsis: new biomarkers for old expectations. Critical Care. 2014 Feb 12;18(1):108.

19. Kumar A, Roberts D, Wood KE, et al. Duration of hypotension before initiation of effective antimicrobial therapy is the critical determinant of survival in human septic shock. Crit Care Med. 2006 Jun;34(6):1589-96.

20. Lee JW. Fluid and electrolyte disturbances in critically ill patients. Electrolyte Blood Press. 2010 Dec;8(2):72-81

21. Muhsin SA, Mount DB. Diagnosis and treatment of hypernatremia. Best Pract Res Clin Endocrinol Metab. 2016 Mar;30 (2):189-203.

22. Adrogue HJ, Madias NE. Hypernatremia. N Engl J Med. 2000 May 18;342(20):1493-9

23. O'Donoghue SD, Dulhunty JM, Bandeshe HK, et al. Acquired hypernatraemia is an independent predictor of mortality in critically ill patients. Anaesthesia. 2009 May;64(5):514-20.

24. Darmon M, Timsit JF, Francais A, et al. Association between hypernatraemia acquired in the ICU and mortality: a cohort study. Nephrol Dial Transplant. 2010 Aug;25(8):2510-5.

25. Hoorn EJ, Betjes MG, Weigel J, et al. Hypernatraemia in critically ill patients: too little water and too much salt. Nephrol Dial Transplant. 2008 May;23(5):1562-8

26. Lindner $\mathrm{G}$, Kneidinger $\mathrm{N}$, Holzinger $\mathrm{U}$, et al. Tonicity balance in patients with hypernatremia acquired in the intensive care unit. Am J Kidney Dis. 2009 Oct;54(4):674-9.

27. Polderman KH, Schreuder WO, Strack van Schijndel RJ, et al. Hypernatremia in the intensive care unit: an indicator of quality of care? Crit Care Med. 1999 Jun;27(6):1105-8.

28. Lindner G, Funk GC, Schwarz C, et al. Hypernatremia in the critically ill is an independent risk factor for mortality. Am J Kidney Dis. 2007 Dec;50(6):952-7.

29. Lindner G, Funk GC, Lassnigg $A$, et al. Intensive careacquired hypernatremia after major cardiothoracic surgery is associated with increased mortality. Intensive Care Med. 2010 Oct;36(10):1718-23. 
58 - The Journal of Critical Care Medicine 2020;6(1)

30. Waite MD, Fuhrman SA, Badawi $O$, et al. Intensive care unit-acquired hypernatremia is an independent predictor of increased mortality and length of stay. J Crit Care. 2013 Aug;28(4):405-12.

31. Van De Louw A, Shaffer C, Schaefer E. Early intensive care unitacquired hypernatremia in severe sepsis patients receiving 0.9\% saline fluid resuscitation. Acta Anaesthesiol Scand. 2014 Sep; 58(8):1007-14.

32. Bodonyi-Kovacs G, Lecker SH. Electrolyte-free water clearance: a key to the diagnosis of hypernatremia in resolving acute renal failure. Clin Exp Nephrol. 2008 Feb;12(1):74-8.

33. Lindner G, Schwarz C, Funk GC. Osmotic diuresis due to urea as the cause of hypernatraemia in critically ill patients.
Available online at: www.jccm.ro Nephrol Dial Transplant. 2012 Mar;27(3):962-7.

34. Ho KM, Power BM. Benefits and risks of furosemide in acute kidney injury. Anaesthesia. 2010 Mar;65(3):283-93.

35. Lindner $G$, Kneidinger $N$, Holzinger $U$, et al. Tonicity balance in patients with hypernatremia acquired in the intensive care unit. Am J Kidney Dis. 2009 Oct;54(4):674-9.

36. Pazmino PA, Pazmino BP. Treatment of acute hypernatremia with hemodialysis. Am J Nephrol. 1993; 13(4):260-5.

37. Park HS, Hong YA, Kim HG, et al. Usefulness of continuous renal replacement therapy for correcting hypernatremia in a patient with severe congestive heart failure. Hemodial Int. 2012 Oct;16(4):559-63 